\title{
ANALISIS PENGENDALIAN PERSEDIAAN BAHAN BAKU KAIN KEMEJA POLOSHIRT MENGGUNAKAN METODE ECONOMIC ORDER QUANTITY (EOQ) DI PT BINA BUSANA INTERNUSA
}

\author{
Khoirun Nissa ${ }^{1},{ }^{*}$, M. Tirtana Siregar ${ }^{2}$ \\ 1 Politeknik APP Jakarta, Kementerian Perindustrian \\ ${ }^{2}$ Politeknik APP Jakarta, Kementerian Perindustrian
}

\begin{abstract}
Abstrak
PT.Bina Busana Internusa adalah perusahaan yang bergerak dibidang garmen dengan memproduksi kemaja pria \& wanita dan seragam kerja khususnya pada Kain kemeja poloshirt yang membutuhkan pengendalian persediaan bahan baku yang baik dan tepat. Produk yang akan diteliti adalah kain kemeja poloshirt. Permasalahan yang terjadi di kain kemeja poloshirt adalah keterlambatan datangnya bahan baku selama 4 hari. Penelitian ini bertujuan untuk mengendalikan persediaan bahan baku menggunakan metode EOQ di PT Bina Busana Internusa. Penelitian ini menggunakan metode EOQ untuk mengetahui total biaya persediaan. Data yang dibutuhkan pada penelitian ini yaitu jumlah pembeliaan bahan baku, jumlah penggunaan bahan baku, biaya simpan, biaya pemesanan, lead time dan frekuensi pemesanan . Hasil yang diperoleh dari metode EOQ yaitu terjadi perbaikan pada pembelian bahan baku, total biaya persediaan bahan baku, frekuensi pemesanan, safety stock dan reorder point. Nilai pembeliaan bahan baku sebesar 1.313,167 kg menjadi $1.837 \mathrm{~kg}$. Nilai total biaya persediaan bahan baku sebesar Rp 2.447.395 menjadi Rp. 2.315.356. Nilai Frekuensi pemesanan sebesar 24 kali menjadi 17 kali. Safety stock yang di hasilkan dari metode EOQ sebesar 749,91 kg. Reorder point yang dihasilkan dari metode EOQ sebesar $969 \mathrm{~kg}$. Oleh karena itu, perusahaan disarankan untuk menimasi total biaya persediaan bahan baku.
\end{abstract}

\author{
Keywords: \\ Pengendalian \\ Persediaan, Bahan Baku, \\ Metode Economic Order \\ Quantity
}

\section{PENDAHULUAN}

Perusahaan manufaktur dibidang garmen memiliki perkembangan yang sangat cepat dan berupaya untuk menjadi yang terbaik dibanding dengan pesaingnya. Hal ini didasarkan semakin tingginya keinginan masyarakat memiliki pakaian yang berkualitas. Sehingga banyak permintaan di pasar swalayan (Matahari Departemen Store dan Counter baju ) dalam kurun waktu beberapa tahun terakhir yang membuat meningkatnya permintaan.

Setiap perusahaan baik itu perusahaan jasa maupun perusahaan manufaktur mempunyai tujuan yang sama yaitu ingin memperoleh laba atau keuntungan. Tetapi untuk mencapai tujuan tersebut tidaklah mudah karena hal itu dipengaruhi oleh beberapa faktor dan perusahaan harus mampu untuk menangani faktor-faktor tersebut. Salah satu faktor yang mempengaruhi yaitu mengenai masalah kelancaran produksi cara dalam penghematan biaya produksi adalah dengan melakukan perencanaan bahan baku yang baik. Perencanaan tidak selamanya berjalan dengan lancar, hal ini menyebabkan jalannya proses produksi terganggu dan perusahaan tidak dapat memproduksi tepat waktu. Sedangkan jika perusahaan melakukan pemenuhan bahan baku yang berlebihan akan menyebabkan biaya inventory yang berlebihan.

PT. Bina Busana Internusa merupakan salah satu perusahaan industri yang bergerak dibidang garmen sejak tahun 1989 dengan memproduksi pakaian kemeja pria \& wanita, dan seragam kerja. Pakaian yang di produksi memiliki 6 merk yaitu Arnold Palmer, Van Heusen, Valino, Kent \& Crew, Sierra Morena dan Harry Martin dengan memiliki produk dan bahan yang berkualitas. Perusahaan ini beroperasi selama 8 - 9 jam dan lembur maksimal selama 2 jam dalam sehari. Perusahaan ini memproduksi pakaian dengan Bahan baku utama adalah kain, interlining dan Aksesoris. Perusahaan penerimaan bahan baku tersebut berasal dari berbagai macam supplier. Oleh sebab itu, Perusahaan perlu dilaksanakan pengendalian bahan baku agar memiliki persediaan yang optimal.

Penelitian ini berfokus pada pakaian kemeja poloshirt dengan merk Arnold Palmer yaitu dengan bahan baku kain yang memiliki masalah dalam hal pemesanan (order), karena pembelian bahan baku 
belum menggunakan metode pengendalian persediaan dan tidak adanya kebijakan mengenai pengadaan jumlah persediaan tambahan untuk dijadikan persediaan pengaman (Safety Stock), serta belum terencananya jadwal untuk pemesanan ulang bahan baku (Reorder Point)., maka terjadi Pemesanan yang jumlahnya kadang tidak sesuai dengan jumlah pemakain bahan baku produk yang akan di produksi. Sehingga persediaan bahan baku terkadang berlebih dan terkadang kekurangan. Jumlah Pemesanan bahan baku yang di pesan tiap pemesanan tidak sesuai dengan jumlah pemakaian bahan baku pada saat pelaksanaan proses produksi. Dimana terdapatnya kekurangan persediaan bahan baku sebesar $18 \mathrm{~kg}$ pada tahun 2016 dan kelebihan bahan baku sebesar 15kg pada tahun 2016, bila kekurangan bahan baku menimbulkan terhambatnya proses produksi bahkan terhenti sehingga proses produksi tidak dapat selesai tepat waktu sesuai dengan jadwal yang telah ditentukan sebelumnya sehingga produk terlambat untuk dikirimkan ke konsumen. Sedangkan kelebihan bahan baku akan menimbulkan biaya persediaan yang besar dan kualitas bahan baku akan menurun bila disimpan dalam waktu yang lama, juga dapat mengurangi mutu produk yang dihasilkan. Maka dari itu perlu ada solusi untuk mengatasi kesulitan di dalam pengendalian bahan baku yang akan digunakan dalam proses produksi, sehingga jumlah bahan baku terkendali, tidak berlebih dan tidak kurang.

Berdasarkan fakta-fakta diatas, maka dalam karya akhir ini penulis menitik beratkan pada pentingnya bahan baku dengan mengambil judul "Pengendalian Persediaan Bahan Baku Kain Kemeja Poloshirt Menggunakan Metode Economic Order Quantity (Eoq) Di Pt Bina Busana Internusa".

\section{METODE}

Berdasarkan sifatnya, penelitian dilakukan dengan penelitian deskriptif survey dengan analisa kuantitatif yang dilakukan dengan tujuan untuk membuat gambaran atau deskripsi tentang keadaan secara objektif yang digunakan untuk memecahkan serta menjawab permasalahan yang telah dihadapi. Pada penelitian ini obyek diamati adalah persediaan dan pengendalian bahan baku Kain., yaitu:

Teknik Pengumpulan Data pada penelitian ini antara lain: 1) Teknik Dokumentasi, mencari data mengenai hal-hal yang berada didalam catatan, buku, notulen, surat, arsip dan sejarah perusahaan. Teknik dokumentasi digunakan untuk mengetahui data mengenai keadaan umum yang berhubungan dengan persediaan dan pengendalian bahan baku dengan menggunakan metode EOQ pada PT. Bina Busana Internusa, diantaranya data pembelian dan penggunaan bahan baku yang terhitung sejak Januari 2016 hingga Desember 2016. Selain data yang dibutuhkan dari PT. Bina Busana Internusa juga dibutuhkannya studi pustaka tentang materi penelitian ini dari berbagai sumber, 2) Wawancara, kegiatan ini berupa proses tanya jawab kepada kepala bagian gudang, kepala bagian produksi dan karyawan-karyawan pada PT Bina Busana Internusa. Dengan dilakukan kegiatan wawancara ini, diharapkan dapat menghasilkan informasi sebagai berikut: a) Data permintaan konsumen selama tahun 2016, b) Data penggunaan bahan baku selama tahun 2016, c) Data biaya-biaya yang dikeluarkan gudang, d) Data proses produksi, 3) Observasi, dilakukan dengan melihat langsung semua aktivitas yang terjadi pada PT. Bina Busana Internusa. Hal ini dilakukan untuk mengetahui mekanisme yang dilakukan pada aktivitas perencanaan dan pengendalian bahan baku. Mulai dari bahan baku dipesan, bahan baku dikirim, bahan baku diterima, sampai bahan baku digunakan.

Hal ini sangat bermanfaat untuk mengetahui keadaan yang sebenarnya dari PT. Bina Busana Internusa agar dapat dijadikan sebagai bahan pembahasan dalam penyusunan penelitian. Waktu penelitian yang dilakukan oleh penulis selama dua bulan, yakni pada bulan 6 Februari - 6 April 2017 . Penelitian ini dilakukan di PT. BINA BUSANA INTERNUSA yang berlokasi di "Kawasan Industri Pulo Gadung B PSP Blok Q No.1, Jl. Polu Buaran II,Jatinegara, Cakung, Jakarta Timur,Daerah Khusus Ibukota Jakarta 13930".

Penyajian data dilakukan dengan menyeleksi data terlebih dahulu sesuai dengan data yang diperlukan dan dibuat dengan bentuk tabel. Dari data yang disajikan dalam bentuk tabel akan dilanjutkan dengan menghitung biaya pemesanan setiap kali pesan dan biaya penyimpanan persatuan bahan baku. Setelah itu menghitung pembelian bahan baku per sekali pesan dengan kebijakan perusahaan. Dari hasil perhitungan pembelian bahan baku per sekali pesan kemudian dapat menghitung total biaya persediaan bahan baku dengan kebijakan perusahaan. Setelah didapatkan hasil perhitungan pengendalian bahan baku menurut kebijakan perusahaan, agar dapat dibandingkan dengan menggunakan metode eoq, harus dilakukan perhitungan pengendalian bahan baku menggunakan metode eoq dengan langkah langkah sebagai berikut: 1) Menghitung jumlah pembelian bahan baku per sekali pemesanan yang ekonomis menggunakan metode eoq, 2) Menghitung pemesanan bahan baku menggunakan metode eoq, 3) Menghitung total biaya pemesanan menggunakan metode eoq, 4) Menghitung persediaan pengamanan (Safety Stock), 5) Menghitung titik pemesanan kembali (Reorder Point). 
Setelah didapatkan hasil perhitungan pengendalian bahan baku menggunakan metode eoq. Kemudian membuat perbandingan antara pengendalian bahan baku menggunakan kebijakan perusahaan dengan menggunakan metode eoq. Setelah didapatkan hasil mana yang lebih baik dan efisien kemudian dilakukan pemilihan kebijakan persediaan oleh PT Bina Busana Internusa

\section{HASIL DAN PEMBAHASAN}

Pengunaan bahan baku kain kemeja poloshirtmemperoleh bahan baku dari berbagai supplier. Bahan baku yang tersedia di gudang sebagian besar digunakan untuk proses produksi dan sebagian disimpan untuk cadangan produksi berikutnya maupun sebagai cadangan apabila sewaktu-waktu kesulitan mendapatkan bahan baku di pasar. Data tentang pengunaan bahan baku di PT Bina Busana Internusa dapat dilihat pada Tabel 1

Tabel 1

Data Penggunaan Bahan Baku tahun 2016

\begin{tabular}{ccc}
\hline No & Bulan & $\begin{array}{c}\text { Jumlah Penggunaan Bahan Baku } \\
\text { (Kg) }\end{array}$ \\
\hline 1. & Januari & 2.914 \\
2. & Febuari & 2.843 \\
3. & Maret & 2.649 \\
4. & April & 2.506 \\
5. & Mei & 2.732 \\
6. & Juni & 2.894 \\
7. & Juli & 1.682 \\
8. & Agustus & 2.624 \\
9. & September & 2.519 \\
10. & Oktober & 1.779 \\
11. & November & 3.162 \\
12 & Desember & 3.212 \\
& Jumlah & 31.516 \\
\hline
\end{tabular}

Sumber : PT Bina Busana Internusa 2016

Untuk menentukan jumlah pembelian bahan baku kain dengan 2 kali pemesanan dalam satu bulan maka dalam satu tahun melakukan pemesanan 24 kali pemesanan pada perusahaan Bina Busana Internusa dapat di hitung sebagai berikut:

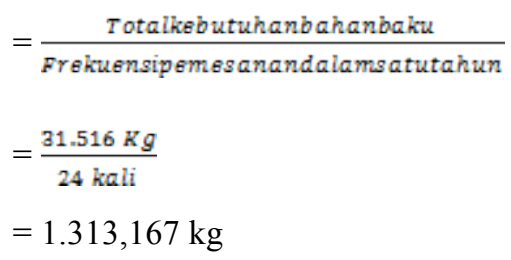

Jadi rata-rata jumlah pembelian bahan baku setiap pemesanan adalah $1.313,167 \mathrm{~kg}$

Biaya pemesanan di PT Bina Busana Internusa terdiri dari: 1) Biaya telepon, 2) Biaya administrasi, 3) Biaya pengangkutan tersedia dalam Tabel 2 Berikut ini. 
Tabel 2

Data Pemesanan Bahan Baku tahun 2016

\begin{tabular}{rlc}
\hline No. & \multicolumn{1}{c}{ Biaya-Biaya } & Jumlah \\
\hline 1. & Biaya telepon & Rp.300.000 \\
2. & Biaya Administrasi & Rp. 120.000 \\
3. & Biaya pengangkutan & Rp. 1.200 .000 \\
& Jumlah & Rp. 1.620.000 \\
\hline
\end{tabular}

Sumber : Hasil Wawancara tahun 2017

Dilihat dari Tabel 4.4 terlihat bahwa dari diantara ketiga biaya yaitu biaya telepon, biaya bongkar pengangkutan dan biaya administrasi, biaya terbesar adalah biaya administrasi. Untuk menghitung besarnya biaya pemesanan sekali pesan maka dapat dihitung dengan rumus :

$$
\begin{aligned}
& =\frac{\text { Total biaya pemesanan }}{\text { frekuensi pemesanan dalam satu tahun }} \\
& =\frac{R p \cdot 1.620 .000}{24 \mathrm{kali}} \\
& =\text { Rp. } 67.500
\end{aligned}
$$

Jadi, Biaya pemesanan dalam 1 kali pesan pada PT Bina Busana Internusa sebesar Rp. 67.500

Biaya-biaya penyimpanan yang dikeluarkan karena perusahaan melakukan penyimpanan dan pengadaan persediaan bahan baku. Biaya-biaya penyimpanan di PT Bina Busana Internusa terdiri dari : 1) Biaya Listrik, 2) Biaya Sewa 90 M, 3) Biaya Tenaga Kerja, terdapat pada Tabel 3 berikut ini.

Tabel 3

Data Penyimpanan Bahan Baku Tahun 2016

\begin{tabular}{ccc}
\hline No. & Biaya - biaya & Jumlah \\
\hline 1. & Biaya Listrik & Rp. 3.772 .289 \\
2. & Biaya Sewa & Rp. 16.740 .000 \\
3. & Biaya Tenaga Kerja & Rp. 19.200 .000 \\
& Total & Rp. $\mathbf{3 9 . 7 1 2 . 2 8 9}$ \\
\hline
\end{tabular}

Sumber : Hasil Wawancara tahun 2017

Untuk menghitung biaya penyimpanan per unit dapat dihitung dengan rumus :

$$
\begin{gathered}
=\frac{\text { Total biaya penyimpanan }}{\text { Total Kebutuhan Bahan Baku }} \\
=\frac{R p .39 .712 .289}{31.516 \mathrm{Kg}}=\mathrm{Rp} 1.260 / \mathrm{Kg}
\end{gathered}
$$

Total Biaya persediaan bahan baku kain pada PT Bina Busana Internusa dihitung: 1) Total kebutuhan bahan baku (D) $31.516 \mathrm{~kg}$, 2) Pembelian rata-rata bahan baku (Q) $1.313 \mathrm{Kg}, 3$ ) Biaya pesan sekali pesan (S) Rp. 67.500, 4) Biaya penyimpanan per unit (H) Rp.1.260.

perhitungan Total Biaya Persediaan:

$\mathrm{TIC}=\left(\frac{D}{Q} s\right)+\left(\frac{Q}{2} H\right)$ 


$$
\begin{aligned}
& =\left(\frac{31.516 \mathrm{Kg}}{1.313 \mathrm{Kg}} R p \cdot 67.500\right) \\
& +\left(\frac{1.313 \mathrm{Kg}}{2} R p \cdot 1.260\right) \\
& =\text { Rp. } 1.620 .205+\text { Rp. } 827.190 \\
& =\text { Rp. } 2.447 .395
\end{aligned}
$$

Jadi total biaya persediaan bahan baku kain yang ditanggung oleh PT Bina Busana Internusa sebesar Rp. 2.447.395

Persediaan pengaman (Safety Stock) sangat penting dalam sebuah perusahaan karena berfungsi untuk melindungi atau menjaga kemungkinan terjadi kekurangan bahan baku, sehingga memperlancar kegiatan proses produksi. Dalam perhitungan persediaan pengaman, rata-rata bahan baku dengan pemakaian bahan baku sesungguhnya dibandingkan kemudian dicari penyimpangannya. Perhitungan standar deviasi dapat dilihat pada Tabel 4 berikut.

Tabel 4

Perhitungan Standar Deviasi

\begin{tabular}{ccccc}
\hline Bulan & $\begin{array}{c}\text { Kebutuhan } \\
\text { bahan baku } \\
\mathbf{( K g )}\end{array}$ & $\begin{array}{c}\text { Perkiraan } \\
\mathbf{Y}\end{array}$ & $\begin{array}{c}\text { Deviasi } \\
\mathbf{( x - y )}\end{array}$ & $\begin{array}{c}\text { Kuadrat } \\
\mathbf{( x - y )} \mathbf{~}^{\mathbf{2}}\end{array}$ \\
\hline Januari & 2.914 & $2.626,33$ & 287,67 & $82.752,11$ \\
Febuari & 2.843 & $2.626,33$ & 216,67 & $46,944,44$ \\
Maret & 2.649 & $2.626,33$ & 22,67 & 513,78 \\
April & 2.506 & $2.626,33$ & $-120,33$ & $14.480,11$ \\
Mei & 2.732 & $2.626,33$ & 105,67 & $11.165,44$ \\
Juni & 2.894 & $2.626,33$ & 267,67 & $71.645,44$ \\
Juli & 1.682 & $2.626,33$ & $-944,33$ & $891.765,44$ \\
Agustus & 2.624 & $2.626,33$ & $-2,33$ & 5,44 \\
September & 2.519 & $2.626,33$ & $-107,33$ & $11.520,44$ \\
Oktober & 1.779 & $2.626,33$ & $-847,33$ & $717.973,78$ \\
November & 3.162 & $2.626,33$ & 535,67 & $286.938,78$ \\
Desember & 3.212 & $2.626,33$ & 585,87 & $343.005,44$ \\
& 31.516 & & & $2.478 .710,67$ \\
\hline
\end{tabular}

Sumber : Data perusahaan yang telah diolah

$\mathrm{y}=\frac{D}{n}=\frac{31.516}{12 \text { bulan }}=2.626$,

$$
\begin{gathered}
=\sqrt{\frac{2.478 .710,67}{12}}=\sqrt{206.559,22} \\
=454,49
\end{gathered}
$$

Khoirun Nissa, M. Tirtana Siregar (2017) . 
Dengan pemakaian asumsi bahwa PT Bina Busana Internusa menerapkan persediaan yang memenuhi permintaan 95\% dan persediaan cadangan 5\%, sehingga dapat diperoleh $\mathrm{Z}$ dengan table normal sebesar 1,65 deviasi standar diatas dari rata-rata.

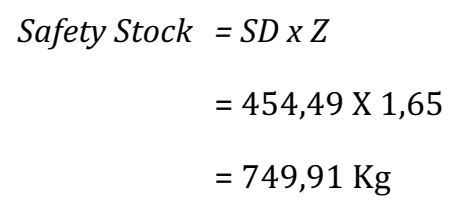

Persediaan pengaman yang harus ada pada tahun 2016 adalah sebesar 749,91 Kg.

Dari perhitungan safety stock diatas, dapat diketahui jumlah persediaan yang dapat dicadangkan sebagai pengaman kelangsungan proses produksi dari resiko kehabisan bahan baku. Persediaan pengaman sebesar ini akan tetap dipertahankan walaupun bahan bakunya dapat diganti yang baru.

Saat pemesanan kembali atau Re Order Point adalah saat dimana perusahaan melakukan pemesanan bahan bakunya kembali, sehingga penerimaan bahan baku yang dipesan dapat tepat waktu. Karena dalam melakukan pemesanan bahan baku tidak dapat langsung diterima itu juga. Besarnya sisa bahan baku yang masih tersisa hingga perusahaan harus melakukan pemesanan kembali sebesar ROP yang telah dihitung. Waktu tunggu (lead time) yang diperlukan PT Bina Busana Internusa untuk menunggu datangnya bahan baku yang telah dipesan rata-rata 2 minggu. Dengan rata-rata jumlah hari kerja 288 hari dalam setahun.

Sebelum menghitung besarnya ROP (Re Order Point), perlu dicari tingkat penggunaan bahan baku perhari. Untuk menentukan tingkat penggunaan bahan baku perhari dapat dihitung dengan cara sebagai berikut: $\mathrm{U}=\frac{D}{t}$

$$
\begin{aligned}
& =\frac{31.516 \mathrm{Kg}}{288 \text { hari }} \\
& =109,43 \mathrm{Kg}
\end{aligned}
$$

Maka titik pemesanan kembali adalah :

$\mathrm{ROP}=\mathrm{U} \times \mathrm{L}+\mathrm{SS}$

$=109,43 \times 2+749,91$

$=969 \mathrm{Kg}$

Pada tahun 2016 perusahaan harus melakukan pemesanan kembali pada saat persediaan bahan baku sebesar $969 \mathrm{Kg}$.

Hasil perhitungan dengan menggunakan kebijakan perusahaan dan menggunakan metode EOQ telah diketahui, sehingga dapat dibandingkan untuk memperoleh hasil yang lebih efesien. Perbandingan dapat dilihatpada Tabel 5 berikut.

\section{Tabel 5}

Perbandingan Kebijakan Perusahaan dengan Metode EOQ

\begin{tabular}{cccc}
\hline No & Keterangan & Kebijakan Perusahaan & Metode EOQ \\
\hline 1. & $\begin{array}{c}\text { Pembelian Rata - } \\
\text { rata Bahan Baku }\end{array}$ & $1.313,167 \mathrm{Kg}$ & $1.837 \mathrm{Kg}$ \\
2. & $\begin{array}{c}\text { Total Biaya } \\
\text { Persediaan Bahan } \\
\text { baku }\end{array}$ & Rp. 2.447 .395 & Rp. 2.315 .356 \\
3. & Frekuensi & 17 Kali \\
\hline
\end{tabular}




\begin{tabular}{ccc}
\hline 4. & Safety Stock & $749,91 \mathrm{Kg}$ \\
5. & Re Order Point & $969 \mathrm{Kg}$ \\
\hline
\end{tabular}

Sumber :Data perusahaan yang telah diolah

Dalam sub bab ini, peneliti akan menguraikan langkah - langkah dalam pengolahan data, berdasarkan data yang diperoleh dari PT. Bina Busana Internusa. perhitungan Economic Order Quantity (EOQ) yang berguna untuk menentukan banyaknya frekuensi pemesanan, jumlah pemesanan, total biaya persediaan bahan baku, penentuan persediaan pengaman (safety stock) dan penentuan pemesanan kembali (reorder point). Berikut langkah-langkah pengolahan data :

Metode EOQ

Perhitungan dengan menggunakan metode Economic Order Quantity (EOQ)

a. Pembelian Bahan baku yang ekonomis

Dengan berdasarkan pada :

1. Biaya penyimpanan bahan baku per unit $(\mathrm{H}) \quad$ Rp. 1.260

2. Total kebutuhan bahan baku (D) $31.516 \mathrm{Kg}$

3. Biaya pesan sekali pesan (S) Rp. 67.500

Maka besarnya pembelian bahan baku yang ekonomis dapat diperhitungkan dengan metode EOQ sebagai berikut :

$$
\begin{aligned}
& \mathrm{EOQ}=\sqrt{\frac{2 D S}{H}} \\
& \mathrm{EOQ}=\sqrt{\frac{2(31.516 \mathrm{Kg})(R p \cdot 67.500)}{R p \cdot 1.260}} \\
& \mathrm{EOQ}=\sqrt{\frac{4.254 \cdot 660.000}{R p \cdot 1.260}} \\
& \mathrm{EOQ}=\sqrt{3.376 .714} \\
& \mathrm{EOQ}=1.837 \mathrm{Kg}
\end{aligned}
$$

Jadi jumlah pembelian bahan yang telah dihitung dengan

menggunakan metode EOQ sebesar $1.837 \mathrm{Kg}$.

b. Frekuensi Pemesanan Bahan baku

Frekuensi pemesanan menurut Metode Economic Order Quantity (EOQ) dapat dihitung dengan cara sebagai berikut:

$$
\begin{aligned}
& \mathrm{I}=\frac{R}{E O Q} \\
& \mathrm{I}=\frac{31.516 \mathrm{~kg}}{1.837 \mathrm{Kg}} \\
& \mathrm{I}=17,156 \text { kali (Dibulatkan }=17 \mathrm{kali})
\end{aligned}
$$

Pemesanan dalam 1 tahun melakukan 17 kali pemesanan dengan perhitungan metode EOQ, maka pembelian akan terjadi jika adanya permintaan dari konsumen. Jadi frekuensi pemesanan bahan baku dengan perhitungan metode EOQ dilakukan 17 kali pemesanan pertahun.

c. Total Biaya Persediaan Bahan Baku

Untuk menghitungkan total biaya persediaan bahan baku, telah diketahui sebagai berikut: 
1. Total kebutuhan bahan baku (D) $31516 \mathrm{Kg}$

2. Biaya pesan 1 kali pesan (S) $\quad$ Rp. 67.500

3. Biaya penyimpanan per unit (H) Rp. 1.260

4. Pembelian bahan baku yang ekonomis(EOQ) $1.837 \mathrm{Kg}$

Perhitungan total biaya persediaan (ITC) adalah sebagai berikut:

$$
\operatorname{TIC}=\left(\frac{D}{Q} s\right)+\left(\frac{Q}{2} H\right)
$$

$\left(\frac{31.516 \mathrm{Kg}}{1.837 \mathrm{Kg}} R p \cdot 67.500\right)+$

$$
\left(\frac{1.837 \mathrm{Kg}}{2} R p \cdot 1.260\right)
$$

$=$ Rp. $1.158 .046+$ Rp. $\quad 1.157 .310$

$=$ Rp. $2 \cdot 315 \cdot 356$

Jadi, total biaya persediaan bahan baku yang telah dihitung dengan menggunakan metode EOQ sebesar Rp. 2.315.356.

\section{SIMPULAN DAN SARAN}

Dari hasil penelitian dan pembahasan uraian-uraian dari Bab IV, maka dapat ditarik kesimpulan antara lain: 1) Menurut kebijakan perusahaan pembelian rata-rata bahan baku kain kemeja poloshirtadalah sebanyak 1.313,167 Kg, sedangkan menurut metode Economic Order Quantity (EOQ) jumlah pembelian rata-rata bahan baku kain kemeja poloshirtyang optimal adalah sebanyak $1.837 \mathrm{Kg}, 2$ ) Menurut kebijakan perusahaan Frekuensi pemesanan sebanyak 24 kali pemesanan dalam satu tahun, sedangkan dihitung dalam metode Economic Order Quantity (EOQ) pemesanan lebih efesiensi adalah 17 kali pemesanan dalam satu tahun, 3) Jumlah persediaan pengaman (safety stock) bahan baku periode 2016 kain kemeja poloshirtyang dibutuhkan oleh PT Bina Busana Internusa adalah 749,91 Kg. Titik pemesanan bahan baku kembali (reorder point) periode 2016 yang dibutuhkan oleh PT.Bina Busana Internusa dengan menggunakan Economic Order Quantity(EOQ) untuk kain kemeja poloshirt adalah 969 $\mathrm{Kg}$, 4) Menurut kebijakan perusahaan total biaya persediaan adalah sebesar Rp. 2.447.395, sedangkan perhitungan metode Economic Order Quantity (EOQ) total biaya persediaan adalah sebesar Rp.2.315.356. Perhitungan metode EOQ total persediaan bahan baku lebih hemat sebesar Rp.132.039dibandingan dengan kebijakan perusahaan.

Dengan berdasarkan kesimpulan yang diperoleh maka penulis dapat memberikan saran kepada perusahaan sebagai pertimbangan dalam kebijakan pengadaan bahan baku, antara lain: 1) Perusahaan hendaknya untuk menggunakan Economic Order Quantity(EOQ) sebagai bahan pertimbangan dalam upaya menghindari resiko kehabisan bahan baku dan juga kelebihan bahan baku sehingga proses pengendalian persediaan dapat terlaksana lebih efisien dan efektif. Untuk lebih memudahkan perhitungan tersebut dapat memperhatikan data yang tersaji sebagai berikut, 2) PT Bina Busana Internusa khususnya bagian gudang perlu mengadakan persediaan pengaman untuk mencegah kekurangan bahan baku pada saat proses produksi sedang berlangsung dan menentukan waktu dan jadwal yang tepat untuk melakukan pemesanan kembali bahan baku agar kelancaran produksi, 3) Perusahaan hendaknya melakukan pemesanan kembali untuk menghindari keterlambatan pemesanan bahan baku agar biaya penyimpanan digudang dapat optimal, 4) Perusahaan sebaiknya menentukan persediaan maksimum untuk menghindari resiko kehabisan dan kelebihan bahan baku sehingga dapat meminimasikan biaya bahan baku bagi perusahaan 


\section{DAFTAR PUSTAKA}

Ahyari, Agus. 1995. Efisiensi Persediaan Bahan. Yogyakarta: BPFE-Yogyakarta.

Assauri, Sofjan. 2004. Manajemen Produksi dan Operasi, Edisi Revisi. Jakarta: Lembaga Penerbit Fakultas Ekonomi Universitas Indonesia.

Dhawyscientist, , Metode Pengendalian Persediaan EOQ(Economic Order Quality), 28 January 2015

Handoko, Hani. 2008. Dasar-dasar Manajemen Produksi dan Operasi, Edisi I. Yogyakarta: BPFEYogyakarta.

Kholmi, Masiyal. 2003 .Akuntasi Biaya. Edisi Empat. Yogyakarta: BPFE

Mulyadi.2002.Akuntasi Biaya.Edisi ke 5.Yogyakarta:Aditia Media.

Mulyono, Sri. 2007. Riset Operasi, Edisi Revisi. Jakarta: Lembaga Penerbit Fakultas Ekonomi Universitas Indonesia.

Nasution,Arman Hakim dan Yudha Prasetyawan.2008.Perencanaan \& Pengendalian Produksi,Edisi I. Yogyakarta: Graha Ilmu.

Nurhayati, Yayat dan H. Acep Komara. 2013. Pengaruh Pasokan Bahan Baku Terhadap Proses

Rangkuti, Freddy. 2007. Manajemen Persediaan (Aplikasi Di Bidang Bisnis).Jakarta:PT. Raja Grafindo Persada.

Sumber Lain:

Indrayati, Rike.2007. pengendalian persediaan bahan baku dengan metode EOQ pada PT Tipota Furnishings Jepara

http://www.binabusana.com/about/business-history 